\title{
PROPOSTA DE EXPANSÃO DA FERRAMENTA API_PC (AVALIAÇÃO DO POTENCIAL DE INOVAÇÃO NO PROJETO CONCEITUAL): UMA ABORDAGEM FUNDAMENTADA EM CRITÉRIOS ORIENTADOS À INOVAÇÃO
}

Juliane de Bassi Padilha (julianepadilha@utfpr.edu.br) - PPGEM, Universidade Tecnológica Federal do Paraná.

Carlos Cziulik (cziulik@utfpr.edu.br) - PPGEM, Universidade Tecnológica Federal do Paraná.

Paulo André de Camargo Beltrão (beltrao@utfpr.edu.br) - PPGEM, Universidade Tecnológica Federal do Paraná.

\section{RESUMO}

O encurtamento do ciclo de vida dos produtos, aliado à busca por diferenciação, cria um cenário cuja inovação torna-se uma demanda necessária. Porém, para que esta ocorra é preciso haver um ambiente orientado à criação e desenvolvimento de produtos inovadores. O Projeto Conceitual consiste numa fase na qual muitas das decisões relacionadas ao produto final são definidas. Portanto, tem-se nesta etapa um campo fértil para o desenvolvimento de conceitos potencialmente inovadores. A literatura identifica ferramentas que auxiliam o processo de seleção de alternativas conceituais, dentre as quais, a Ferramenta API_PC (Avaliação do Potencial de Inovação no Projeto Conceitual). $O$ presente artigo tem por objetivo conduzir a expansão dos critérios e subcritérios apresentados na Ferramenta API_PC. Por meio de uma análise reversa (similarmente a da ferramenta API_PC), juntamente com a revisão de literatura, é possivel confirmar elou identificar novos critérios relacionados ao âmbito da inovação. As decisões de projeto na fase conceitual são significativas para o sucesso do produto em desenvolvimento e podem interferir na qualidade, no custo e na diferenciação do produto final. A utilização de uma ferramenta de projeto orientada ao potencial de inovação permite criar um mecanismo robusto que de forma consistente identifica soluções potencialmente inovadoras.

Palavras-chave: Desenvolvimento de produtos; avaliação de alternativas conceituais; potencial inovador

Área: Melhoria do Processo de Desenvolvimento de Produtos e Serviços

\section{INTRODUÇÃ̃O}

O atual cenário de competição nacional e internacional aponta o grau de competitividade como um fator fundamental para as organizações. Esta competitividade está apoiada em requisitos como qualidade, custo e tempo para o desenvolvimento de um produto. Aliado a isto, está o consumidor cujo acesso à informação acentua a busca por produtos diferenciados. Para completar este cenário, o encurtamento no ciclo de vida dos produtos é notório, apontando para a necessidade do lançamento de novos produtos em um período de tempo cada vez menor (CORAL; OGLIARI; ABREU, 2008, KO; KUO, 2010).

A inovação é um elemento essencial no PDP (processo de desenvolvimento de produto) uma vez que agrega valor aos produtos. A orientação adequada das etapas de projeto pode reduzir 
o tempo de desenvolvimento do produto, bem como fomentar as possibilidades de sucesso do mesmo. Dentro das etapas que compõem o PDP, é na fase do projeto conceitual que muitas das decisões relacionadas ao novo produto são direcionadas. Apesar das empresas terem conhecimento da importância do PDP no crescimento dos negócios a um longo prazo, a taxa de falhas em novos produtos é alta. De acordo com Salgado et al. (2010) uma das razões mais significativas é a pouca utilização de modelos, ferramentas e técnicas para auxiliar o PDP.

A literatura referencia ferramentas de projeto que contribuem no processo de seleção de alternativas conceituais. A Ferramenta API_PC - Avaliação do Potencial de Inovação no Projeto Conceitual (PADILHA, 2008) busca, por meio de critérios e subcritérios orientados à inovação, auxiliar a equipe de projeto no processo de seleção de conceitos com maior potencial inovador. Partindo dos critérios apontados pela ferramenta, em conjunto com uma nova análise reversa (no mesmo padrão da utilizada pela API_PC) e uma revisão de literatura, propõe-se o mapeamento de novos critérios e subcritérios.

A partir daí, tem-se a expansão da Ferramenta API_PC, a qual pretende direcionar a avaliação de alternativas conceituais de forma consistente, auxiliando a equipe de projeto na seleção do conceito que apresente maior possibilidade de se converter em um produto potencialmente inovador.

\section{INOVAÇÃO E PROJETO CONCEITUAL}

O projeto de produto agrega valor aos negócios, pois converte objetivos, intenções e ideias em objetos concretos, os quais o consumidor está disposto a obter (TAKAHASHI; TAKAHASHI, 2007). Portanto, tratar a inovação de forma sistematizada durante as fases de projeto permite o desenvolvimento de novos produtos em um espaço de tempo previsto, mapeando as etapas do PDP e resgatando informações de modo a orientar o conhecimento gerado.

O Projeto Conceitual compreende uma etapa, dentro do PDP, na qual são gerados os conceitos que poderão dar origem a produtos inovadores (BACK et al, 2008). Sendo assim, identificar oportunidades de inovação nesta fase pode contribuir na busca pela diferenciação e consequentemente, no aumento da competitividade. Justel et al. (2007) descrevem quatro fases que o processo de seleção de conceitos deve apresentar: i) listar os conceitos a avaliar; ii) definir os critérios de seleção; iii) definir o nível de cumprimento de cada conceito em relação ao critério de seleção; e iv) através de um algoritmo de seleção, determinar o melhor conceito.

A geração, avaliação e seleção de conceitos é uma das mais importantes tarefas no desenvolvimento de um novo produto. Segundo Li et al. (2010) as deliberações nesta etapa permitem determinar o quão inovador o produto poderá ser. Erros nesta fase podem comprometer 70 a $80 \%$ do investimento no produto. Tratar a inovação em todas as fases do PDP torna-se uma necessidade emergente nos esforços pela diferenciação. O tópico seguinte abordará algumas ferramentas que contribuem para o processo de seleção de ideias, destacando a Ferramenta API_PC.

\subsection{Ferramentas para a seleção de ideias}

A literatura aponta diversos métodos que orientam o processo de seleção de alternativas. Nesta seção, são destacados alguns dos métodos/ ferramentas existentes.

Stevanović, Marjanović e Storga (2016) ressaltam que a seleção de ideias é, muitas vezes, conduzida de modo intuitivo sendo que apenas um pequeno número de empresas têm definidos os métodos para avaliação das mesmas. Os autores também destacam os problemas 
que podem surgir como métricas indefinidas e a imprecisão na definição das variáveis utilizadas no processo de avaliação do potencial de inovação das ideias.

Nikander, Liikkanen e Laakso (2013) apresentam, por meio de um experimento, critérios implícitos e explícitos que orientam a seleção de ideias, tendo sido "novidade", o critério mais utilizado.

Kudrowitz e Wallace (2013) expõem um método de triagem de ideias (NUF - novel, useful, feasible) no qual, a partir de três atributos - novidade, utilidade e viabilidade, é possível avaliar as alternativas de projeto. Este método é indicado quando o conjunto solução contém grande quantidade de ideias.

Rozenfeld et al. (2006) apontam o Método da Matriz de Decisão como sendo um meio de avaliar alternativas conceituais. A partir de uma concepção escolhida como referência faz-se a avaliação das demais concepções por meio de critérios de avaliação, podendo "inovação" fazer parte de um dos critérios.

Back et al. (2008) destacam que o processo de seleção de alternativas pode ocorrer em duas etapas. Os métodos empregados na primeira etapa são mais intuitivos (listagem de prós e contras, melhor ou pior); já os da segunda etapa compreendem a atribuição de pesos e valoração de critérios, de modo a ordenar as concepções. Neste caso é adotada uma matriz de avaliação por comparação aos pares, na qual cada critério é comparado aos demais.

Frederiksen e Knudsen (2017) relatam uma abordagem para avaliar o potencial de inovação de ideias. A abordagem é embasada na revisão de literatura a respeito de criatividade e inovação e parte de três critérios: i) novidade; ii) utilidade; e iii) potencial de mercado. Kirova (2009) determina oito grupos de critérios os quais permitem avaliar potencial de inovação com base na capacidade da organização para desenvolver novas ideias.

Justel et al. (2007) apresentam um método para avaliação e seleção de conceitos a partir de três aspectos relativos ao grau de novidade e seu potencial de sucesso no mercado. São eles: i) grau de novidade do conceito do produto; ii) solicitações do cliente; e iii) especificações e viabilidade comercial. Estes aspectos foram integrados numa matriz QFD modificada. O primeiro aspecto relativo ao grau de novidade é obtido por meio do cruzamento de informações a partir da determinação de nove tipos de descontinuidades identificadas pelos autores. O segundo aspecto relacionado ao grau de novidade é a patenteabilidade, na qual conceitos considerados patenteáveis são inovadores.

Padilha (2008) apresenta a Ferramenta API_PC a qual busca identificar, dentro de um conjunto solução homogêneo, a alternativa que possua maior potencial de se converter em um produto inovador. A ferramenta parte de seis critérios desmembrados em subcritérios através dos quais as alternativas conceituais são submetidas a um processo de avaliação e seleção. A seleção é feita por meio de pesos estabelecidos aos critérios e subcritérios existentes na ferramenta.

Todos os métodos apresentados buscam auxiliar a equipe de projeto na tomada de decisão, englobando diversos aspectos inerentes ao projeto de produto. Em algumas abordagens "novidade" é apresentada como um dos atributos de avaliação (NIKANDER, LIIKKANEN, LAAKSO, 2013; KUDROWITZ, WALLACE, 2013; ROZENFELD et al., 2006; BACK et al., 2008). Em outras, o potencial de inovação é apresentado mediante grupos de critérios baseados na capacidade criativa, na capacidade da organização em produzir novas ideias e no sucesso de mercado (FREDERIKSEN, KNUDSEN, 2017; KIROVA, 2009; JUSTEL et al., 2007). 
A Ferramenta API_PC (PADILHA, 2008) parte da avaliação de conceitos por meio de grupos de critérios divididos em subcritérios, orientados à busca pela solução com maior potencial de inovação. A avaliação ocorre de forma direta, na qual o conceito avaliado contempla ou não determinado critério. Na sequencia a ferramenta identifica o conceito potencialmente inovador por meio da maior pontuação.

Com o objetivo de mapear novos critérios, bem como reiterar os existentes na Ferramenta API_PC, foi conduzida uma nova análise reversa nos mesmos moldes da que foi desenvolvida para a ferramenta, seguido do embasamento teórico que dá suporte à expansão dos critérios.

\section{EXPANSÃO DA FERRAMENTA API_PC}

A expansão da ferramenta proposta é caracterizada como uma pesquisa aplicada, cuja metodologia adotada é de caráter exploratório, pois os fundamentos teóricos (revisão de literatura para identificar novos critérios) são apoiados por dados empíricos (análise reversa). Para revisão de literatura foram consultados livros referentes ao tema proposto bem como diversos journals por meio das bases de dados Scopus e ScienceDirect. A análise reversa visa reforçar, através de uma ilustração prática, os argumentos levantados pela literatura. Os elementos levantados por meio da análise reversa foram cruzados com os da revisão de literatura, juntamente com os critérios já existentes na Ferramenta API_PC. Com isso, é formada uma nova estrutura de critérios para a ferramenta proposta, na qual ocorre a adição de novos critérios bem como a confirmação dos critérios existentes.

A análise reversa apresenta quatro produtos inovadores. A seleção de três, dos quatro produtos, partiu do Catálogo da Bienal de Design 2010 (último disponibilizado). Procurou-se identificar premiações que estes produtos receberam de modo a estabelecer um "júri" que justifique o caráter inovativo dos mesmos. Apenas o produto Clever Caps não está no Catálogo da Bienal por ser posterior ao mesmo.

O Quadro 1 apresenta a análise reversa, contendo a descrição geral do produto. Em seguida, são destacados os prêmios recebidos. Após, são apresentadas as características específicas de cada produto, procurando enfatizar os elementos caracterizadores das inovações. Ao final de cada sentença, é realçado (em negrito) o critério identificado. Alguns destes, já pertencentes à Ferramenta API_PC; outros, identificados nesta nova análise reversa.

Quadro 1. Análise reversa

\begin{tabular}{|c|c|c|c|c|}
\hline$/$ & TRIKKE & CLEVER CAPS & WAP O3 & CHILD PROOF \\
\hline 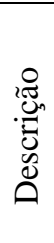 & $\begin{array}{l}\text { Veículo de propulsão } \\
\text { humano semelhante a } \\
\text { um patinete. } \\
\text { Ano: } 2000\end{array}$ & $\begin{array}{l}\text { Tampa de garrafa que se } \\
\text { encaixa à outra e é } \\
\text { compatível com blocos de } \\
\text { montar como Lego. } \\
\text { Ano: } 2014\end{array}$ & $\begin{array}{l}\text { Lavadora de alta } \\
\text { pressão compacta que } \\
\text { utiliza o ozônio para } \\
\text { realizar higienização. } \\
\text { Ano: } 2010\end{array}$ & $\begin{array}{c}\text { Sistema de tampa à } \\
\text { prova de crianças. } \\
\text { Ano: } 2010\end{array}$ \\
\hline 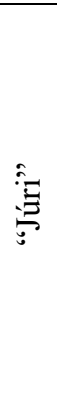 & $\begin{array}{l}\text { • Revista Time } \\
\text { "Melhores invenções } \\
\text { de 2002"; } \\
\text { - Bienal de Design } \\
\text { 2010. }\end{array}$ & $\begin{array}{l}\text { - iF Design Award } 2014 \\
\text { (duas categorias - bebidas } \\
\text { e formato embalagem); } \\
\text { - Prêmio Brasileiro de } \\
\text { Embalagem Embanews; } \\
\text { - Eleita entre os } 80 \\
\text { designs mais impactantes } \\
\text { do mundo pelo London } \\
\text { Design Museum. }\end{array}$ & $\begin{array}{c}\text { - Bienal Brasileira de } \\
\text { Design } 2010 .\end{array}$ & $\begin{array}{l}\text { - Bienal Brasileira } \\
\text { de Design 2010; } \\
\text { - Apontada como } \\
\text { uma das principais } \\
\text { inovações em } \\
\text { embalagem na Pack } \\
\text { Expo International, } \\
\text { feira do setor de } \\
\text { packing, Chicago- } \\
\text { EUA em 2010. }\end{array}$ \\
\hline
\end{tabular}

continua 


\begin{tabular}{|c|c|c|c|c|}
\hline & & & & onclusão \\
\hline & TRIKKE & CLEVER CAPS & WAP O3 & CHILD PROOF \\
\hline 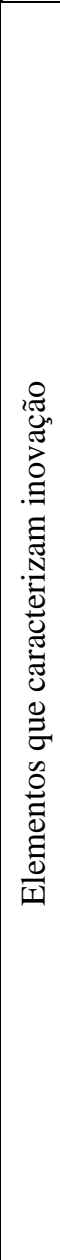 & $\begin{array}{l}\text { - Para operar o veículo, } \\
\text { o usuário dá o impulso } \\
\text { inicial, ao mesmo tempo } \\
\text { em que movimenta o } \\
\text { triciclo para o lado. A } \\
\text { repetição do movimento } \\
\text { mantém o veículo em } \\
\text { movimento, sem } \\
\text { necessidade de colocar o } \\
\text { pé no chão. Critério } \\
\text { função } \\
\text { - Todos os produtos são } \\
\text { dobráveis e podem ser } \\
\text { colocados em uma } \\
\text { espécie de maleta, que } \\
\text { pode ser carregada como } \\
\text { uma mochila, ou a } \\
\text { tiracolo. Critério } \\
\text { acondicionamento } \\
\text { - Expansão da linha de } \\
\text { produtos (2006). } \\
\text { Critério forma } \\
\text { - No Japão, o produto } \\
\text { sofreu adaptações do } \\
\text { ponto de vista } \\
\text { ergonômico, destinado } \\
\text { ao público japonês. } \\
\text { Critério ergonomia }\end{array}$ & $\begin{array}{l}\text { - As tampas atendem aos } \\
\text { três critérios de um produto } \\
\text { sustentável: } \\
\text { ecologicamente corretas, } \\
\text { socialmente justas e } \\
\text { acessíveis e } \\
\text { economicamente viáveis } \\
\text { para a indústria. Critério } \\
\text { sustentabilidade } \\
\text { - Reutilização do produto } \\
\text { para uma nova função: de } \\
\text { tampa de garrafa podem ser } \\
\text { utilizadas na composição } \\
\text { de diversos objetos como } \\
\text { luminária, mobiliário, } \\
\text { brinquedos, porta objetos, } \\
\text { entre outros. Critério } \\
\text { função } \\
\text { - A empresa pretende } \\
\text { lançar novos modelos, } \\
\text { tamanhos e formatos. As } \\
\text { tampas também são } \\
\text { montáveis entre si. } \\
\text { Critério forma }\end{array}$ & $\begin{array}{l}\text { - O produto utiliza uma } \\
\text { tecnologia já conhecida } \\
\text { antes, mas jamais } \\
\text { utilizada para este fim. } \\
\text { Critério tecnologia } \\
\text {-Utiliza uma tecnologia } \\
\text { que vem sendo } \\
\text { acompanhada nos } \\
\text { usuários e no meio } \\
\text { ambiente. O produto, } \\
\text { até o momento, se } \\
\text { mostrou } \\
\text { ambientalmente } \\
\text { seguro. Critério } \\
\text { sustentabilidade } \\
\text { - O produto utiliza um } \\
\text { material já conhecido } \\
\text { (ozônio) mas não } \\
\text { utilizado para o fim } \\
\text { proposto. Critério } \\
\text { material } \\
\text { - O produto } \\
\text { implementa a mesma } \\
\text { função que os produtos } \\
\text { similares (limpeza) } \\
\text { mas de um modo } \\
\text { significativamente } \\
\text { diferente (usando } \\
\text { ozônio). Critério } \\
\text { função }\end{array}$ & $\begin{array}{l}\text { - Redução na } \\
\text { quantidade de peças e } \\
\text { materiais, o que } \\
\text { facilita o processo de } \\
\text { manufatura e } \\
\text { reciclagem. Critério } \\
\text { manufatura e } \\
\text { critério } \\
\text { sustentabilidade } \\
\text { - O produto permite } \\
\text { diferentes arranjos } \\
\text { utilizando o mesmo } \\
\text { gargalo. Critério } \\
\text { forma }\end{array}$ \\
\hline
\end{tabular}

Fonte: Adaptado de Trikke (2015); Centro de Design do Paraná (2010); Clever Pack (2015); WAP (2009).

Com o intuito de dar seguimento à identificação de novos elementos e consequente expansão da ferramenta, são apresentados os critérios/ subcritérios (em ordem alfabética) juntamente com a revisão de literatura referente ao PDP, os quais reforçam e apoiam a identificação dos critérios.

a) Transporte/ Acondicionamento: Os subcritérios apresentados compreendem, além do transporte e distribuição, a embalagem e acondicionamento da solução. Portanto, na expansão da Ferramenta API_PC, a denominação deste critério foi alterada de Transporte para Acondicionamento.

$\mathrm{Na}$ análise reversa o produto Trikke distingue-se pela facilidade de transporte por apresentar uma solução dobrável, sendo facilmente acondicionado.

b) Ergonomia: Na Ferramenta API_PC, o critério Ergonomia apresentou um subcritério. Neste estudo foram adicionados mais três subcritérios com base na análise dos produtos e na revisão de literatura. Kirova (2009) apresentou uma metodologia que visa avaliar o potencial de inovação de modo que a organização gere e desenvolva ideias, produtos e processos. Dentre os oito grupos de critérios, o autor aponta "simplicidade e conveniência do uso" e "ergonomia e satisfação do consumo" como componentes que permitem avaliar o potencial de inovação. Ylmaz e Seifert (2011) 
apontam heurísticas de projeto as quais pretendem identificar possíveis variações de conceitos, de modo a gerar um conjunto solução mais diversificado. Dentre as heurísticas apresentadas, "Ajustar de acordo com as diferentes necessidades dos usuários" e "Alterar o modo como o usuário interage fisicamente com o sistema" integram referências teóricas que permitem o desmembramento deste critério em mais subcritérios.

Além disso, na análise reversa o produto Trikke oferece a possibilidade de adaptação ergonômica do produto para públicos distintos (e.g. adulto, teen, kids), além de uma versão do produto direcionada ao público japonês.

c) Forma: A Ferramenta API_PC apresentou quatro subcritérios para Forma. Foram adicionados dois subcritérios também baseados nas heurísticas apontadas por Ylmaz e Seifert (2011). "Repetir a mesma forma várias vezes" e "Inverter as formas repetidas para diversas funções" são as heurísticas que justificam a inserção do subcritério "A solução permite diferentes arranjos a partir da repetição e/ou inversão de um mesmo elemento formal" e a heurística "Alterar a configuração utilizando os mesmos elementos de design" a que fundamenta o subcritério "A solução prevê a criação de uma família de produtos em edições posteriores". Vickery et al. (2016) destacam a influência positiva que o uso da modularidade pode trazer ao PDP, podendo ser um atributo de diferenciação conforme subcritério "A solução é modular podendo estar prevista a adição de novos componentes em edições posteriores do produto". $\mathrm{O}$ subcritério "A solução possui algum nível de personalização (e.g. cores, composições, texturas)" destaca a personalização como sendo uma oportunidade para desenvolver inovações, conforme exposto por Ko e Kuo (2010). Os autores apontam a personalização de produtos em massa como sendo uma oportunidade de promover maior variedade de produtos. O subcritério "A solução prevê a criação de uma família de produtos em edições posteriores" relaciona a criação de famílias de produtos como uma estratégia para oferecer diversidade nas soluções, conforme evidenciado por Kubota et al. (2013).

$\mathrm{Na}$ análise reversa, o produto Trikke expandiu sua linha de produtos, permitindo a criação de uma família de produtos voltada para diferentes públicos. As tampas Clever Caps viabilizaram o lançamento de novos modelos, tamanhos e formatos, além de as peças serem montáveis entre si. As tampas Child Proof possibilitaram diferentes arranjos utilizando o mesmo gargalo.

d) Função: A Ferramenta API_PC apresentou três subcritérios para Função. A heurística "Utilizar um elemento comum para funções múltiplas" proposta por Ylmaz e Seifert (2011) em conjunto com a interação e integração de novos arranjos para os elementos funcionais proposta por Rozenfeld et al. (2006) podem permitir que soluções conceituais sejam tidas como potencialmente inovadoras por apresentarem estas características. A metodologia proposta por Kirova (2009) apontou os itens "modo de realização da função", "melhoria e expansão da função" e "melhoria da tecnologia para a realização da função desejada e do processo de produção necessário" como elementos que permitem avaliar o potencial de inovação.

$\mathrm{Na}$ análise reversa, o produto Trikke apresentou um novo modo de se locomover, diferente dos produtos existentes no mercado. As tampas Clever Caps oportunizaram a definição de uma nova função para um produto já existente. A lavadora de alta pressão Wap O3 permitiu a execução da mesma função que os produtos similares, mas de um modo diferente.

e) Mantenabilidade: Este critério não é apresentado na Ferramenta API_PC. Entretanto, na literatura Back et al. (2008) apresentam um conjunto de critérios que representam atributos típicos de produtos e que podem servir de referência na determinação dos 
elementos de avaliação de concepções, sendo mantenabilidade um deles. Este critério incorporado à Ferramenta API_PC pode ser desmembrado em dois subcritérios: um referente à manutenção executada pelo próprio usuário e outro referente à manutenção conduzida em uma assistência técnica.

f) Manufatura: $\mathrm{Na}$ Ferramenta API_PC, o critério Manufatura apresentou três subcritérios. Na reestruturação proposta para a ferramenta, optou-se por deslocar dois subcritérios da configuração original para a criação de um novo critério - "Material". Utilizando as heurísticas "Adicionar, tirar ou dobrar componentes que não estiverem em uso", "Substituir um elemento por outro" e "Dividir uma forma em vários elementos menores" propostas por Ylmaz e Seifert (2011) é possível definir os subcritérios "A solução prevê redução no número de componentes/partes do produto sem haver comprometimento funcional" e "A solução prevê uma melhora significativa no processo de montagem na produção".

$\mathrm{Na}$ análise reversa, as tampas Child Proof permitiram redução na quantidade de peças e materiais, sem trazer prejuízo ao produto reforçando os subcritérios adicionados.

g) Material: Conforme citado acima, dois subcritérios foram deslocados do critério Manufatura e passaram a compor o critério "Material". Kirova (2009), na metodologia proposta para avaliar o potencial de inovação, apontou o item "possibilidade de introdução de novos materiais e elementos" como um meio de potencializar a inovação em produtos. Do mesmo modo, Rozenfeld et al. (2006) evidenciam a importância da seleção de materiais e de como muitas vezes as empresas restringem a oportunidade de inovar pelo uso de um novo material ou uma nova forma de se utilizar um material já conhecido.

$\mathrm{Na}$ análise reversa, a lavadora de alta pressão Wap O3 utilizou um componente já conhecido (ozônio) que foi adaptado a um novo produto, ressaltando os aspectos levantados nos subcritérios definidos acima.

h) Sustentabilidade: A Ferramenta API_PC não abordou este critério. Back et al. (2008) apresentam, dentro do conjunto de critérios que representam atributos típicos de produtos os parâmetros "impacto ambiental", "reciclabilidade" e "descartabilidade", os quais podem ser incorporados como subcritérios dentro do critério "Sustentabilidade". $\mathrm{Na}$ avaliação dos produtos selecionados foi identificado o parâmetro "sustentável" como sendo uma característica que agregou valor e que pode diferenciar uma solução das demais, como foi o caso das tampas Clever Caps que permitiram um novo uso ao produto após seu uso. As tampas Child Proof previram redução na quantidade de peças e materiais, facilitando a reciclagem. A lavadora de alta pressão Wap O3 constatou que o uso do ozônio para o fim proposto não trouxe prejuízos ao meio ambiente, sendo um fator que agregou diferenciação em relação aos produtos similares existentes.

i) Tecnologia: Ao critério Tecnologia foram atribuídos mais dois subcritérios, no sentido de caracterizar a abordagem do uso de tecnologia em uma solução. Tondolo et al. (2012) apontam o desenvolvimento de novas tecnologias como elemento para diferenciação em produtos. Back et al. (2008) apresentaram atributos específicos de produtos, dentre os quais "forças", "energia", "sinais", "automação" e "tempo" podem servir de base para identificação de soluções tecnologicamente diferenciadas.

A Figura 01 ilustra um esquema com os critérios e seus desmembramentos. Os retângulos em branco referem-se aos subcritérios já existentes na ferramenta analisada. Os retângulos em cinza, , aos subcritérios adicionados. Há, ainda, um tracejado indicando o deslocamento de dois subcritérios do critério "Manufatura" para o critério "Material". O contorno em traço-ponto destaca os critérios que foram adicionados (Sustentabilidade, Material e Mantenabilidade). 
Figura 1. Estrutura dos critérios e seus desmembramentos. Fonte: Padilha (2008)

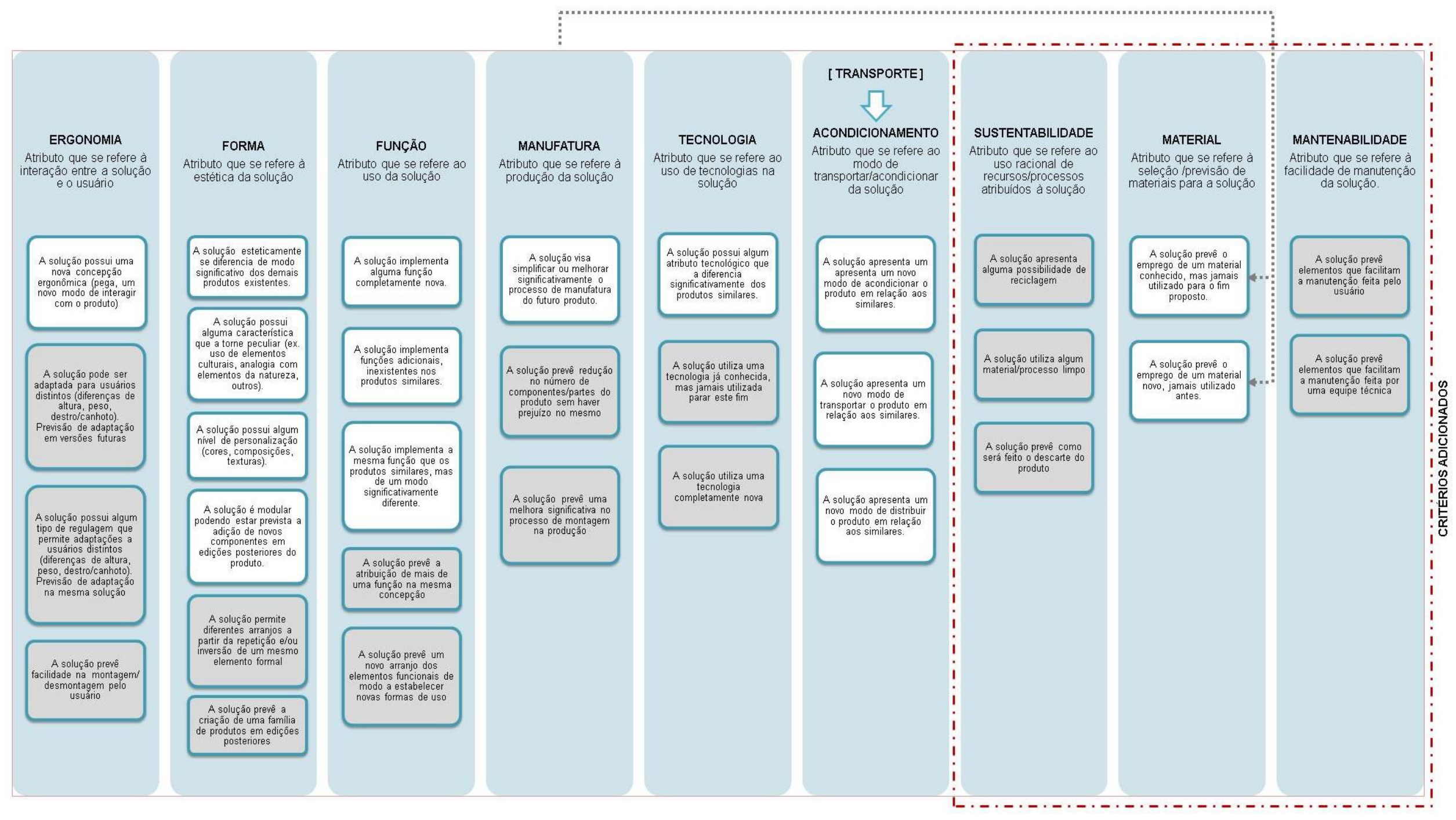


O mapeamento de novos critérios e subcritérios permitiu aperfeiçoar um mecanismo consistente o qual possibilita a avaliação de alternativas conceituais sob a ótica do potencial de inovação. A utilização de uma abordagem que contemplou uma análise reversa em conjunto com a revisão de literatura permitiu ampliar a Ferramenta API_PC e intensificar a busca pela solução que possa se converter em um produto inovador.

\section{CONSIDERAÇÕES FINAIS}

A expansão da Ferramenta API_PC ocorreu por meio da adição de critérios e subcritérios embasados em uma análise reversa juntamente com uma revisão de literatura. Tratar aspectos relacionados à inovação nas fases iniciais do PDP favorece o desenvolvimento de produtos potencialmente inovadores. A fase do projeto conceitual constitui um campo fértil para inovação uma vez que permite a ideação, avaliação e seleção de conceitos que, devidamente orientados podem resultar em produtos inovadores, contribuindo na diferenciação e aumento da competitividade das organizações.

\section{REFERÊNCIAS}

BACK, N. et al. Projeto Integrado de Produtos: planejamento, concepção e modelagem. Barueri: Manole, 2008.

CENTRO DE DESIGN PARANÁ. Catálogo bienal brasileira de design 2010. Curitiba, 2010. $384 \mathrm{p}$.

CLEVER PACK. Clever Caps: sustentabilidade posta em prática. Disponível em: < http://www.cleverpack.com.br/clever-caps/> Acesso em 20 maio 2017

CORAL, E. et al. Gestão Integrada da Inovação: estratégia, organização e desenvolvimento de produtos. São Paulo: Atlas, 2008.

FREDERIKSEN, M. H.; KNUDSEN, M. P. From creative ideas to innovation performance: the role of assessment criteria. Creativity and Innovation Management. V. 26, n. 1, p. 60-74, 2017.

JUSTEL, D. L. Evaluation method for selecting innovative product concepts with greater potential marketing success. In: International Conference on Engineering Design, 16th ed. Paris, 2007

KIROVA, M. Methods for evaluation of the innovation potential. Journal of Entrepreneurship and Innovation, v 1, p.30-40, 2009.

KO, Y.; KUO, P. Modeling concurrent design method for product variety. Concurrent Engineering: Research and Applications, v18, n.3, p.207-217, 2010.

KUBOTA, F. I. et al. Desenvolvimento de plataforma de produto e modularidade: uma análise bibliométrica. Teoria e Prática em Administração, v.3, n.2, p.44-69, 2013.

KUDROWITZ, B. M.; WALLACE, D. Assessing the quality of ideas from prolific, earlystage product ideation. Journal of Engineering Design, V. 24, p. 120-139, 2013.

LI, W. et al. The process model to aid innovation of products conceptual design. Expert Systems with Applications, v.37, n.5, p.3574-3587, 2010.

NIKANDER, J. B.; LIIKKANEN, L. A.; LAAKSO, M. Naturally emerging decision criteria in product concept evaluation. In: INTERNATIONAL CONFERENCE ON ENGINEERING DESIGN, 19, 2013, Seul. Anais... Seul, 2013. 
PADILHA, J. B. Ferramenta para avaliação de alternativas na etapa conceitual de desenvolvimento de produto: uma abordagem baseada em critérios de inovação. 2008. 145 f. Dissertação (Mestrado em Engenharia Mecânica e de Materiais) - Universidade Tecnológica Federal do Paraná, Curitiba, Brasil, 2008.

ROZENFELD, H. et al. Gestão de Desenvolvimento de Produtos: uma referência para a melhoria do processo. São Paulo: Saraiva, 2006. 542 p.

SALGADO, E. G. et al. Modelos de referência para desenvolvimento de produtos: classificação, análise e sugestões para pesquisas futuras. Revista Produção Online, v.10, n.4, p.886-911, 2010.

STEVANOVIĆ M. et al. Idea management in product innovation: the empirical research results. Tehnički Vjesnik, v.23, n.5, p.1285-1294, 2016.

TAKAHASHI, Sérgio; TAKAHASHI, Vania Passarini. Gestão da Inovação de Produtos: estratégia, processo, organização e conhecimento. Rio de Janeiro: Campus, 2007.

TONDOLO, R. P. et al. A interação da estratégia competitiva e custos no processo de desenvolvimento de produto. Revista Espacios, v.33, n.3, 2012.

TRIKKE. Produtos. Disponível em: <http://trikke.com.br/index.php?option=com_content\&view=article\&id=53\&Itemid=74> Acesso em 20 maio 2017.

VICKERY, S. K. et al. Product modularity, process modularity and new product introduction performance: does complexity matter? Production and Operations Management, v.25, n.4, p.751-770, 2016.

WAP revoluciona mercado de higienização com nova lavadora à base de Ozônio. Revista geração sustentável, Curitiba, 29 nov. 2009. Disponível em < http://revistageracaosustentavel.blogspot.com.br/2009/11/wap-revoluciona-mercado-dehigienizacao.html> Acesso em 25 maio. 2017.

YILMAZ, S.; SEIFERT, C. Creativity through design heuristics: a case study of expert product design. Design Studies, v.32, n.4, p.384-415, 2011. 